\title{
TIME OBSERVANCE AND PRODUCTIVE PERFORMANCE OF CIVIL SERVANTS: POLICY IMPLICATIONS
}

\author{
Liza Jacinto Macasukit Gernal ${ }^{1}$ \\ Sonayah Guimba ${ }^{2}$ \\ Rommel Pilapil Sergio ${ }^{3}$
}

DOI: https://doi.org/10.31410/ERAZ.2019.25

\begin{abstract}
This study is about time observance and productive performance among employees in the selected city governments in the Philippines. Principally, it attempts to determine if performance of employees is influenced by time observance. Specifically, it is concerned with the level of productive performance among civil servant respondents $(n=1,142)$ as gauged by the attainment of targets and performance rating, the influence of time observance to productive performance, the time-related problems encountered by the civil servant respondents; and lastly, the suggested solution to the time related problems encountered by the respondents. This study utilized the qualitative, descriptive method that employed primary data. A structured questionnaire has been used to explore the set of variables proposed in this study as they apply to local situations. The present study explored the Filipino concept and utilization of official time and how this bears on the performance of their official function. The results of the study concur that in dealing with employees, one must consider individual's idiosyncrasy. In the case of the small minority of sampled employees whose time observance had been marked by tardiness and absenteeism, supervisors must make it their responsibility to observe them individually so that appropriate solutions can be applied. The 90 percent of the sample who were punctual among the respondents does not pose as a problem insofar as punctuality is concerned. To reinforce the positive behavior of this group and to provide encouragement of the small minority who came to the office either tardy or absent, inculcation on the benefits of wise use of mandated time must be done.
\end{abstract}

Keywords: Time observance, productive performance, civil servants, policy implications.

\section{INTRODUCTION}

$\mathrm{T}$ hroughout the history, professionals have seen the importance of time orientation, a system of complying to the prescribed standards of the company.

"Time is Gold", the saying goes. This is heavy with implication for people who are conscious of their time. Time is a resource that is both necessary and indispensable. It is one thing that man cannot do with. "It is", Drucker (1967) describes, "the one truly universal condition". As to time in an organization, it connotes that it is the most valuable commodity.

Such that time is totally irreplaceable, it has to be properly utilized to make advantage of its optimal value. To the extent that man is able to manage his time determine his success or failure not only as a business individual but also as a human being (Mc Cay, 1959).

As Hall and Hursch (1982) has observed, time management is one great paradox. People complain about not having enough time yet it is all they have. As Sison (1994) emphasizes, time itself is not the problem, but how it is being utilized.

\footnotetext{
$1 \quad$ Al Ain University of Science and Technology, Al Ain, United Arab Emirates

2 Mindanao State University, Philippines

3 Canadian University Dubai, Dubai, United Arab Emirates
} 
The proper observance of office time is a primary indicator of performance. It does not only result to an increase in the volume of output being produced; it enhances organizational efficiency as well (Andreas, 1981, 1993). Indeed, as Kettering notes, "management needs more than men, materials and machines to make profits. It needs a system which prevents the waste of time and effort, that is waste of money." (Bittel, 1991; Osborne and Gaebler, 1993; Parkinson, 1979; Sherman, Bohlander, and Chuden, 1988; and Steers, 1984).

Nowhere is this truer than in the government service, where efficiency of performance is of paramount value to the public for the people, they who make the "business of government" possible, deserve not only a responsive but also a prompt delivery of services. The Philippine Constitution mandates public offices and employees to serve the people with utmost responsibility, integrity, loyalty and efficiency (Art. XI, Sec. 1). This can only be realized when the employees report to their workstations regularly and punctually and make use of this official time for productivity.

It is then to this effect that the Civil Service Commission, which is the central personnel agency of the government, has prescribed the standard office hours for workers in the civil service. Such government hours "shall be from eight o'clock to twelve o'clock noon and from one o'clock to five o'clock in the afternoon (Executive Order 292).

Despite these official policies on government time, problems exist in government agencies. Absenteeism and tardiness continue to be common occurrences. In a survey conducted by one agency, for example, it was shown that employee absenteeism and tardiness rate was 10.16 percent. In concrete terms, this meant that 75 employees are completely absent from the office for the whole year (DOLE Manager's Page, 1992).

When certain employees are absent, the number of personnel actually available for a given task is likewise reduced (Flippo, 1984), affecting directly the efficient delivery of public service. Tardiness, too, bears upon both the employee's effectiveness and organizational productivity.

The slogan campaign of the Civil Service Commission "Mamamayan Muna Hindi Mamaya Na" (People's interest first, not anything else) addresses the need for behavioral reforms in the bureaucracy, particularly, by which civil servants deal with the public (Mamamayan Muna, Hindi Mamaya Na! Primer). This implies prevalence of mañana habit in the government bureaucracy. Mañana habit means putting off for what can be done today (Health and Home, 1994). This is very obvious in the delays of transactions in government agencies. As they have always been, governments are known for their sluggishness and low productivity.

It is in this light that the researchers have pushed for the study related to the time observance and productive performance of government civil servants which emphasis on policy implications. 


\section{RESEACH STATEMENT}

This study attempted to describe the official time utilization among employees in Marawi, Iligan and Cagayan de Oro City, Philippines and how this affected productive performance.

Consequently, it sought to answer the following questions:

1. What is the level of productive performance among sampled civil servants as a gauge in the attainment of targets and in the performance, rating adopted by their respective agencies?

2. Does time observance influence productive performance among respondents?

3. What are the time-related challenges encountered by both the subordinate civil servants and their supervisors?

4. What implications to policy do the sampled civil servants recommend to solve the time-related problems they have encountered?

\section{LITERATURE REVIEW}

While government labor and the business cycle can have negative impact on productivity, they are not, by themselves, the cause. One of the major factors that cause decline the productivity is management of time (Black, 1976; Crany, Smith, and Stone, 1992; Dale, 1989; Davis and Newstrom, 1989; and Dessler, 1978).

Supervisor has much influence on this directly and by the atmosphere he creates. The main cause of this is usually poor organization of the work, caused by the poor supervision or general management. They are largely to be blamed for they do not object to this apparent inactivity (Andres, 1983; Holley and Jennings, 1983; Leveriza, 1990; and Levesque, 1992).

Another problem that cause the delay of transactions in most government agencies is the lack of preventive measures against time wasters. As much as 25 percent of a typical supervisor's day maybe spend with people who come to the workstation and take up time. In fact, it is not the subordinates who drop in and waste the supervisor's time; it is the supervisor's peers and supervisors many of whom are executive enjoys being with, thus the subordinates tend to entertain their own visitors too thinking that their supervisors well not mind at all. (Executive Digest Vol. 6 \#1, 1985).

Generally, in government offices, the most common time wasters are the visitors coming in and out of the office without appointments. This is very evident in most government agencies here in Marawi, Iligan and Cagayan de Oro City where a lot of people are gathered as if waiting for something very important. However unannounced visitors are not the only time wasters. It is common to find office desks and chairs empty in the provincial offices, cities, towns and barangays because the occupants choose to be tardy or not report at all times, or if not, the occupants are present but are just idling their time playing cards or just staring at blank walls.

Time problems as phenomena can be observed anywhere in the government bureaucracy, as indeed in any organization for that matter. And the city government offices at Marawi, Iligan and Cagayan de Oro are not exception. As to why these persists despite Civil Service rules and regulations to the contrary, it is not exactly known; as to why civil servants behave the way they do, it cannot be easily discerned; and as to the losses incurred on account of these. They must be huge. 
$\mathrm{HO}_{1}$ : Civil servants' time observance as indicated by their punctuality and actual work attendance does not influence productive performance as indicated in the attainment of target output and performance rating.

\section{METHODOLOGY}

This study employed qualitative-descriptive-exploratory design. The present study explored the Filipino concept and utilization of official time and how this bears on the performance of their official function.

The respondents were drawn from the operating level and first line supervisors of all departments in the city governments of Marawi, Iligan and Cagayan de Oro City. The target population of the three cities was 4,522, 466 of whom were from the City Government of Marawi, 1,628 from Iligan City and 2,428 from Cagayan de Oro.

Marawi which is a component city of Lanao Sur is one of the locales of the study. It has an area of 22.6 square miles with a population of 65,000 persons more or less, a large majority of whom belong to the Meranao tribe. Islam is the dominant religion with an estimated composition of 95 percent, the remaining five percent are Christian who migrated from Luzon and Visayas as early as commonwealth period. Although Marawi is richly endowed with natural resources, it is the presence of the Lake Lanao that makes her popular in the region and throughout the nation.

On another hand, Iligan City is popularly and distinctly known by its three names. It is dubbed as the "Industrial Hub of The South"; "Pittsburgh of the Philippines"; and "City of Waterfalls". It is located on the northwest coast of Mindanao and lies on the boundary of Region X and XII. It is bounded on the north by Iligan Bay; on the south by the province of Lanao del Norte and Lanao del Sur; on the east by the province of Misamis Occidental and on the west by the province of Misamis Oriental.

As of 1955, it has a total population of 273,004 of which 31 percent are urban dwellers and 69 percent are rural settlers. It has a limited flat land along the coastline and the topography is rolling and mountainous in the hinterlands.

Another research setting is Cagayan de Oro on the other hand, known far and wide as "City of Golden Friendship". It is a valley nestled between verdant hills rolling down to Macajalar Bay. Tumbling through the heart of the valley is the Cagayan de Oro River, its acre waters reminiscent of the riches once lodged in its depth. It is located on the north by Macajalar Bay; on the south by the provinces of Bukidnon and Lanao del Norte; on the east by the Municipality of Tagoloan; and on the west by the Municipality of Opol.

From the central location along the coastline of Northern Mindanao, Cagayan de Oro serves as the center of Region X. it is the center of trade, commerce, finance, and education in the region. It is also the focal point of the Cagayan de Oro - Iligan Corridor Special Development Project (C I C - S D P). As of 1995, its total population was 421,314. It is the busiest regional capital in Mindanao. It occupies a total land area of 48,886 hectares of which 5.5 percent are utilized for urban and industry; 73 percent for agriculture; 21.5 percent for agricultural and non-urban. 


\section{PRESENTATION, ANALYSIS AND INTERPRETATION OF DATA}

This section answers the research statements.

The Profile of the Respondents. The respondents of this study were employees of the City Government of Marawi, Iligan and Cagayan de Oro. The sample size of 1,291 was determined using Sloven's formula. The 133 respondents were from Marawi City, 465 from Iligan City and 693 from Cagayan de Oro City, Philippines. There were more employees handling non-supervisory position than supervisory ones. The sampled respondents were regular employees of the three cities whose salaries, fringe benefits and other compensations were determined in accordance with the strict provisions of law, circulars from the joint commission on Local Government Personnel Administration and Executive Orders from the Office of the President.

As government employees, the respondents are subject to Civil Service Rules and Regulation relative to recruitment, tenure of office, status of employment, retirement and are expected to deliver quality balances to the public.

The level of productive performance among sampled civil servants as gauged in the attainment of targets and the performance rating adopted their respective agencies. As reflected in the Table 1, 240 or 30 percent of the 804 respondents said that 100 percent of the daily normal workload was accomplished for most working days, while 214 or 26 percent said only 25 percent of the normal workload was being accomplished for the period of 24 months being studied. For the rest of respondents, 237 representing 29 percent accomplished 75 percent workload and 114 or 15 percent accomplished 50 percent of the daily workload in most days of the twenty-four-month periods. The study however, did not include analysis of workload compatibility with standards, so that it cannot be ascertain if these accomplishing 100 percent of target had lower load than the standard set, on those accomplishing the least percentage of completion had higher load.

Table 1: Distribution of the Respondents by their Attainment of Targets

\begin{tabular}{l|c|c}
\hline \hline ATTAINMENT OF TARGETS & FREQUENCY & PERCENTAGE \\
\hline \hline $1.25 \%$ or $1 / 4$ most working hours & 214 & 26.0 \\
$2.50 \%$ or $1 / 2$ most working hours & 114 & 15.0 \\
$3.75 \%$ or $3 / 4$ most working hours & 237 & 29.0 \\
$4.100 \%$ or most working hours & 240 & 30.0 \\
TOTAL & ----- & 100.0 \\
\hline \hline
\end{tabular}

Performance Rating. Hand in hand with attainment of targets in determining performance of civil servants sampled was performance rating. It shows that 895 or 83 percent of the respondents claimed being rated very satisfactory while 3 or 0.27 percent of the 1,077 respondents had poor ratings for the first half of the year while 931 or 86.20 percent were rated very satisfactory and 28 or 2.60 percent had the highest rating of outstanding for the second half of succeeding year. For the first half of first year, 966 or 87.10 percent of the 1,109 respondents were rated very satisfactory while 3 or 0.27 percent had poor ratings while 975 or 87.91 percent were again rated very satisfactory and 1 or 0.09 percent was given a poor rating for second half.

As observed, the city governments follow the guidelines set forth by the Civil Service Commission under MC. No. 12, s. of 1993 which establishes the agencies performance evaluation system. The system contains, among others, the basic policies, the objectives and scope, the 
mechanics of its implementations and the system of rating. The overall rating consists of ( 70 percent) actual performance (indicated by quantity, quality and timeliness) and (30 percent) behavioral dimension (including courtesy, human relations, punctuality and attendance and initiative for non-supervisors, and leadership). Stress tolerance was added, for the supervisors.

Ideally, a planning session is held at the start of the rating period, where the supervisor and the subordinate agree on the targets for the period. While the period of rating covering 6 months is in progress, the supervisor monitors and reviews the performance of the employee such that possible reinforcements can be made if the latter is not hitting his performance targets. In practice, however, the procedure rarely takes place. As generally observed and through interviews, employees just fill up the Performance Evaluation System form, do the rating themselves and have it signed by their supervisors. Sometimes, the setting of targets and the rating itself are simultaneously done during the rating period. With this practice performance rating is assumed rather than actual. The supervisor's maybe partly to be blamed for giving a token rating even if their subordinates do not deserve it.

It should be noted that under the Performance Evaluation System, for an employee to get at least a satisfactory rating (the lowest acceptable rating), he has to meet 100 percent the standards of performance, including compliance with the behavioral aspects of his job. Taking punctuality and attendance as indicators, for example, for one to be at least satisfactory, he should not incur tardiness for at least seven to ten times during the last six months and not to be absent for at least 9 to 12 times (M.C. No. 12, s, 1993).

The preceding analysis established pattern of time observance of respondents and their performance.

The dependency of a productive performance on time observance among respondents. This two sets of variables were being tested to determine relationships, to wit: punctuality and work attendance versus job performance with sub variables target attainment and performance rating. The dependency of the latter was calculated with the use of chi-square the results of which are shown in the succeeding table.

Table 2: Relationship of Punctuality To Attainment of Targets $(n=1,142)$

\begin{tabular}{|c|c|c|c|c|c|c|c|c|c|c|}
\hline \multirow{3}{*}{ PUNCTUALITY } & \multicolumn{10}{|c|}{ ATTAINMENT OF TARGETS } \\
\hline & \multicolumn{2}{|c|}{$25 \%$} & \multicolumn{2}{|c|}{$50 \%$} & \multicolumn{2}{|c|}{$75 \%$} & \multicolumn{2}{|c|}{$100 \%$} & \multicolumn{2}{|c|}{ TOTAL } \\
\hline & $\mathbf{f}$ & $\%$ & f & $\%$ & $\mathbf{f}$ & $\%$ & $\mathbf{f}$ & $\%$ & $\mathbf{f}$ & $\%$ \\
\hline High & 133 & 50.56 & 44 & 30.77 & 226 & 52.27 & 146 & 47.86 & 549 & 48.0 \\
\hline Average & 70 & 26.62 & 39 & 27.23 & 120 & 27.70 & 76 & 24.92 & 305 & 27.0 \\
\hline Low & 60 & 22.8 & 59 & 41.26 & 86 & 19.97 & 83 & 27.71 & 288 & 25.0 \\
\hline TOTAL & 263 & 100 & 142 & 100 & 432 & 100 & 305 & 100 & 1,142 & 100 \\
\hline $\begin{array}{c}\text { Level } \\
\text { of Significance }\end{array}$ & \multicolumn{3}{|c|}{$\begin{array}{l}\text { Chi-Square } \\
\text { Tabular value }\end{array}$} & \multicolumn{5}{|c|}{$\begin{array}{l}\text { Chi-square } \\
\text { Computed }\end{array}$} & \multicolumn{2}{|c|}{ Relationship } \\
\hline .05 & & -------------- & & -- & & \multicolumn{3}{|c|}{----------- } & \multicolumn{2}{|c|}{ Significant } \\
\hline
\end{tabular}

On punctuality of time observance against attainment of targets among sampled employees, Table 2 shows that at significance level of .05, degree of freedom at 6 , the chi-square value 12.59 and computed on at 32.10 indicates positive relationship, which means attainment of targets of sampled employees depends on punctuality of employees in arrival and departure from the 
workplace and breaktime. Or said in another way, the higher the degree of workers punctuality the higher is their attainment of work targets. With this result, the formulated null hypothesis that time observance in terms of punctuality has no significant relationship with performance as indicated in attainment of target is rejected.

The time-related problems encountered by both the subordinate civil servants and their supervisors.

Table 3: The Distribution of Respondents by Challenges Encountered in the Job

\begin{tabular}{l|c|c|c|c}
\hline \multirow{2}{*}{\multicolumn{1}{c|}{ PROBLEMS }} & \multicolumn{2}{c|}{ Supervisory } & \multicolumn{2}{c}{ Non-Supervisory } \\
\cline { 2 - 5 } & Frequency & Percentage & Frequency & Percentage \\
\hline \hline 1. Tardiness of some subordinates & 96 & 66.70 & 429 & 43.00 \\
2. Absenteeism of some subordinates & 67 & 46.52 & 378 & 37.87 \\
3. Undertime of some subordinates & 54 & 37.50 & 240 & 24.00 \\
4. Extended Breaktime of some subordinates & 53 & 36.80 & 337 & 33.76 \\
5. Gossiping during worktime & 52 & 36.11 & 291 & 29.15 \\
6. Slowdown on Assigned Task & 37 & 25.70 & 229 & 22.94 \\
7. Clock watchers of some subordinates & 34 & 23.61 & 141 & 14.12 \\
8. AWOL of some subordinates & 29 & 20.13 & 140 & 14.00 \\
9. Nagging Supervisors & - & - & 136 & 13.62 \\
10. Inattentive Supervisors & - & - & 124 & 12.42 \\
\hline \hline
\end{tabular}

The four major problems encountered were 1) Tardiness (66.7 percent) for supervisory level and (43 percent) for non-supervisory level, 2) Absenteeism (46.52 percent) for supervisory and (37.87 percent) for non-supervisory, 3) Undertime for the supervisors (37.5 percent), 4) Extended breaktime for the non-supervisor (33.76 percent). These four problems have negative implications to the organization as negative behavior per se. Employee attendance and punctuality is a stabilizing factor in any organization. According to Sison (1994), when an employee is absent or late, it affects the efficiency and effectiveness of work performance and consequently, the delivery of services to the public.

Regarding breaktime, the data affirmed the observation noted by Stahl (1983) that "the problem regarding rest period is how to control it, how to keep it from being abused by the few who are not highly motivated". To correct the practice, of spending time for excessive breaks, Stahl (1983) recommends that the manager should look at the quality of supervision, the motivation of employees and the government insistence on reasonable standards of performance and production.

Research also attempted to identify reasons or causes of the four major problems encountered by both supervisors and non-supervisors.

The possible policy-based implications as perceived by the respondents regarding the time-related problems they have encountered. The recommended solutions of both the subordinates and supervisors as respondents were mainly to minimize the occurrence of time related problems in their office such as tardiness, absenteeism, extended breaktime and undertime of some employees. 
Among the frequently suggested solutions are:

1. Proper delegation of responsibility and authority,

2. Employee motivation such as encouraging them to make use of their talents and abilities, and

3. Policies and procedures must be strictly implemented and practiced. It has been noted by some of the supervisors that some of the employees are mismatched with the job. This gives affirmation that many government employees join the government service for the wrong reasons. Many have been appointed in return for a political favor.

\section{SUMMARY OF FINDINGS}

Based on the analysis of the data, the following findings were revealed in this study:

1. Tardiness and absences are the most common time-related problems said to have been encountered by both the supervisors and non-supervisory respondents;

2. Findings show that there is a significant relationship between time observance and productive performance as indicated by their punctuality to attainment of targets and work attendance to attainment of targets. While, punctuality to performance rating and actual work attendance to performance rating shows no significant relationships;

3. 3. Among the solutions suggested by respondents, proper delegation of responsibility and authority, and policies and procedures governing time observance should be made understood by workers.

\section{RECOMMENDATIONS}

In line with the stated findings and conclusion, the study recommends the following:

1. To reinforce the generally satisfactory time observance of civil servants and to provide encouragement to the small minority who are non-observant of time, inculcate in them the value of time use and its benefits, as the findings of this study revealed.

2. This maybe integrated in their regular meetings, or during flag ceremonies. For them to see corrected results, they should be made to set their targets on a weekly basis, monitor and divulge results also during meetings.

3. There is no proper substitute to effective supervision. The department heads and divisions chiefs are responsible for the conduct of their subordinates should realize should realize that good supervision is a prerequisite to proper office decorum. Not only were the supervisors expected to lead by serving as role models, they should also should manage and motivate their people. Perhaps it would help if the supervisors themselves would be held liable for the unbecoming conduct of their subordinates. This after all, is what command responsibility is all about.

4. It was also suggested that the city government officials of Marawi, Iligan, and Cagayan de Oro City should start looking at the motivational factors affecting the employees and efforts should be done to support these. Increasing the pay level of the city government workers might be necessary but this will not be a cure - all, unless something is done about the organizational culture too.

5. The city government of Marawi, Iligan, and Cagayan de Oro through the personnel office should implement training interventions to develop and upgrade the competencies of the supervisors and the rest of the employees. 
6. Furthermore, the city government should adopt its mission statement and a supportive organizational culture should have created to rally behind this mission. This would necessarily entail "reinventing" the bureaucracy.

7. Lastly, a conduct of further researches along based on the herein concepts is highly recommended. While performance rating and time observance formed part of this study, the results tended to be hazy because the investigation on performance rating was perceptual which was discovered only after results were revealed. Conduct of the same study may be done in other national government agencies for comparative purposes. Results from the comparative analysis will hopefully provide extensive as well as in depth insight into the practices of public sector employees.

8. For a more refined approach in determining a better yardstick in measuring workload accomplishment and in-depth analysis on workload. Against standard should be adopted.

\section{REFERENCES}

[1] Andres, Tomas. Management Values: A Sequel to Understanding Filipino Values. New Day Publishers, 1993.

[2] Andres, Tomas D. Understanding Filipino Values: A Management Approach. New Day Publisher, 1981.

[3] Bittel, Lester R. Right on Time: The Complete Guide to Time Pressured Managers. New York: MC Graw Hill, Inc. 1991.

[4] Black, James Menzies. Assignment: Management, A Guide to Executive Command. Prentice hall, Inc, 1976.

[5] Cranny, C. J.; Patricia Caimn Smith and Eugene F. Stone. Job Satisfaction: How People Feel About Their Job and How It Affects Their Performance. New York: Maxwell Macmillan International, 1992.

[6] Dale, Ernets. Management Theory and Practice. $4^{\text {th }}$ ed. New York: MC Graw Hill Book Company, 1989.

[7] Davis, Keith, and John W. Newstrom. Organizational Behavior: Human Behavior at Work. $8^{\text {th }}$ ed. New York: Mc Graw Hill Company, Inc. 1989.

[8] Dessler, Gary. Personnel Management: Modern Concepts and Techniques. Virginia: Teston Publishing Co. Inc, 1978.

[9] Douglass, Merill E., and Douglas, Donna N. Manage Your Time, Manage Your Work, Manage Yourself. Houghton Mefflin Co., Inc.

[10] Drucker, Peter F. The Effective Executive. New York: Harper and Row Publishers, 1967

[11] Flippo, Edwin B. Personnel Management. $6^{\text {th }}$ ed. New York: Mc Graw Hill Book Company, 1984.

[12] Holley, William H., and Kenneth M. Jennings. Personnel Management, Functions and Issues. Chicago: The Dryden Press, 1983.

[13] Leveriza, Jose P. Public Administration: The Business of Government. $2^{\text {nd }}$ ed. Manila: National Book Store Inc., 1990.

[14] Levesque, Joseph O. The Human Resource Problem Solver's Handbook. New York, USA: Mc Graw Hill Inc, 1992.

[15] Mc Cay, James T. The Management of Time. New Jersey, Prentice Hall, Inc. 1959.

[16] Hall, B. L., \& Hursch, D. E. (1982). An evaluation of the effects of a time management training program on work efficiency. Journal of Organizational Behavior Management, 3(4), 73-96. 
[17] Osborne, David and ted Gaebler. Reinventing Government: How The Entrepreneurial Spirit Is Transforming The Public Sector New York: Penguin Books Inc., 1993.

[18] Parkinson, Northecote C. Parkinsons Law. Ballentine Books ed., 1979.

[19] Sherman, Arthur Jr. W., George W. Bohlander, and Herbert J. Chuden. Managing Human Resources. $8^{\text {th }}$ ed. USA: South Western Publishing Co., 1988.

[20] Sison, Perfecto S. Personnel and Human Resource Management. $\quad 6^{\text {th }}$ ed. Manila: Rex Bookstore, 1994.

[21] Stahl, O. Glenn. Public Personnel Administration. $8^{\text {th }}$ ed. New York: Harper and Row Publishers, 1983.

[22] Steers, Richard M. Introduction to Organizational Behavior. $2^{\text {nd }}$ ed Illinois: Scott. Freeman and Company, 1984.

\section{Others:}

[23] Constitution of the Republic of the Philippines

[24] Mamamayan Muna, Hindi Mamaya na!: Primer 1994

[25] The Manager's page Department of Interior and Local Government, Volume III No. 7, 1992

[26] The Civil Service Laws and Rules

[27] Omnibus Rule Implementing Book V of Executive Order no. 292

[28] World Executive Digest, Vol. 6\#1. 1985 